\title{
Gene expression profile in human induced pluripotent stem cells: Chondrogenic differentiation in vitro, part B
}

\author{
EWELINA AUGUSTYNIAK ${ }^{1,2^{*}}$, WIKTORIA MARIA SUCHORSKA ${ }^{1,3^{*}}$, \\ TOMASZ TRZECIAK ${ }^{4}$ and MAGDALENA RICHTER ${ }^{4}$
}

\author{
${ }^{1}$ Radiobiology Laboratory, Greater Poland Cancer Centre, 61-866 Poznan; \\ ${ }^{2}$ The Postgraduate School of Molecular Medicine, Medical University of Warsaw, 02-091 Warsaw; \\ ${ }^{3}$ Department of Electroradiology, Poznan University of Medical Sciences, 61-866 Poznan; ${ }^{4}$ Department of \\ Orthopedics and Traumatology, Poznan University of Medical Sciences, 61-545 Poznan, Poland
}

Received August 3, 2016; Accepted January 26, 2017

DOI: $10.3892 / \mathrm{mmr} .2017 .6335$

\begin{abstract}
The development of human induced pluripotent stem cells (hiPSCs) is considered a turning point in tissue engineering. However, more data are required to improve understanding of key aspects of the cell differentiation process, including how specific chondrogenic processes affect the gene expression profile of chondrocyte-like cells and the relative value of cell differentiation markers. The main aims of the present study were as follows: To determine the gene expression profile of chondrogenic-like cells derived from hiPSCs cultured in mediums conditioned with HC-402-05a cells or supplemented with transforming growth factor $\beta 3$ (TGF- $\beta 3$ ), and to assess the relative utility of the most commonly-used
\end{abstract}

Correspondence to: Mrs. Ewelina Augustyniak, Radiobiology Laboratory, Greater Poland Cancer Centre, 15 Garbary Street, 61-866 Poznan, Poland

E-mail: ewelina.augustyniak@wco.pl

${ }^{*}$ Contributed equally

Abbreviations: ALPL, alkaline phosphatase; BMP-2, bone morphogenetic protein-2; BMP-4, bone morphogenetic protein-4; CH13L1, chitanise-3-like protein; COL2A1, type II collagen; EBs, embryoid bodies; ECM, extracellular matrix; FGF-2, fibroblast growth factor 2; GDF-5, growth differentiation factor 5; HC-402-05a, human primary chondrocyte cell line; hESCs, human embryonic stem cells; hiPSCs, human induced pluripotent stem cells; IHH, indian hedgehog; MMP, matrix metalloproteinase; PHDFs, primary human dermal fibroblasts; PTHLH, parathyroid hormone related protein; PTHrP, parathyroid hormone-like hormone; RUNX2, runt-related transcription factor 2; SOX5, 6,9 , sex determining region Y-box 5, 6, 9; TGF- $\beta 2$, transforming growth factor $\beta 2$; TGF- $\beta 3$, transforming growth factor $\beta 3$; VEGF, vascular endothelial growth factor

Key words: human induced pluripotent stem cells, differentiation, chondrogenesis, chondrogenic markers, advanced and late chondrogenesis, hypertrophy, ossification, transforming growth factor- $\beta 3$, conditioned medium chondrogenic markers as indicators of cell differentiation. These issues are relevant with regard to the use of human fibroblasts in the reprogramming process to obtain hiPSCs. Human fibroblasts are derived from mesoderm and thus share a wide range of properties with chondrocytes, which originate from the mesenchyme. The hiPSCs were obtained from human primary dermal fibroblasts during a reprogramming process. Two methods, both involving embryoid bodies (EB), were used to obtain chondrocytes from the hiPSCs: EBs formed in the presence of a chondrogenic medium with TGF- $\beta 3$ (10 ng/ml) and EBs formed in a medium conditioned with growth factors from HC-402-05a cells. Based on reverse transcription-quantitative polymerase chain reaction analysis, the results demonstrated that hiPSCs are capable of effective chondrogenic differentiation, with the cells obtained in the HC-402-05a medium presenting with morphological features and markers characteristic of mature human chondrocytes. In contrast, cells differentiated in the presence of TGF- $\beta 3$ presented with certain undesirable hypertrophic characteristics. Several genes, most notably runt-related transcription factor 2, transforming growth factor $\beta 2$ and transforming growth factor $\beta 3$, were good markers of advanced and late hiPSC chondrogenic differentiation, whereas transforming growth factor $\beta 3$ I, II, III receptors and bone morphogenetic protein-2, bone morphogenetic protein- 4 and growth differentiation factor 5 were less valuable. These findings provide valuable data on the use of stem cells in cartilage tissue regeneration.

\section{Introduction}

Articular cartilage has a poor regenerative capacity which often results in joint osteoarthritis, with cartilage degradation as the primary characteristic. Currently available treatments for osteoarthritis yield variable outcomes (1) and for this reason novel treatments are required. One promising alternative is regenerative medicine using stem cells, producing cells that it is possible to differentiate into articular chondrocytes to replenish the damaged cartilage. Initially, researchers focused on somatic stem cells, including bone marrow mesenchymal stem cells, which were considered a potent cell source for 
cartilage repair $(2,3)$. However, their limited proliferative potential made them unsuitable for cartilage regeneration. The search for alternative approaches led to the development of human induced pluripotent stem cells (hiPSCs), which have unrestricted proliferative activity and pluripotency. As hiPSCs are developed from adult human cells, they are free from the ethical concerns associated with human embryonic stem cells (hESCs) (4). HiPSCs are formed by inducing a pluripotent state, usually achieved by overexpression of transcription factors (known as Yamanaka factors) and proteins with varied cellular functions (including RNA-binding protein Lin28) $(5,6)$.

There are numerous techniques used for chondrogenic differentiation of hiPSCs, including micromass culture, directed differentiation, pellet culture and formation of embryoid bodies (EBs) (7-10). Of these methods, the most common and efficient method of obtaining chondrocyte-like cells from hiPSCs is EB formation. However, multiple aspects of this process remain poorly understood, including how the specific medium used for chondrogenic differentiation affects gene expression (11). Likewise, although a wide range of markers are used to assess cell differentiation during the differentiation process, the relative utility of these markers is not well understood (12). As a result, it is difficult to select the optimal medium and markers to achieve optimal cell yield.

It was within this context that the present study was conducted. The present study has two main aims: To determine the gene expression profile of chondrogenic-like cells derived from hiPSCs cultured in medium conditioned with HC-402-05a cells or supplemented with transforming growth factor $\beta 3$ (TGF- $\beta 3$ ), and to determine the relative value of the most commonly used chondrogenic markers as indicators of cell differentiation. The cells were differentiated in chondrogenic mediums supplemented with either TGF- $\beta 3$, the member of the TGF- $\beta$ superfamily with the most chondrogenic potential (13) or conditioned with growth factors from the human primary chondrocyte cell line (HC-402-05a). The gene expression profiles of the chondrogenic-like cells derived from the hiPSCs cultured in the TGF- $\beta$-supplemented medium (TGF- $\beta 3$ medium) was then assessed and compared with the cells cultured in the HC-402-05a-conditioned medium (conditioned medium). The type of medium was demonstrated to have a large impact on the gene expression profiles. A total of 22 different markers of chondrogenic differentiation were also evaluated, and the most promising gene markers of hiPSC differentiation during late stage chondrogenesis were runt-related transcription factor 2 (RUNX2), matrix metalloproteinase-13 (MMP-13), and vascular endothelial growth factor $(V E G F)$, which engaged in the formation of hypertrophic chondrocytes during skeletal development. Useful, however less valuable markers included collagens and members of the TGF- $\beta$ superfamily, which serve functions in several stages of chondrogenesis. Furthermore, the shared mesodermal origin of fibroblasts and chondrocytes should be taken into consideration, as several genes are common between stem cell-derived chondrocytes and human fibroblasts, including SMAD family member 3 (SMAD3) and bone morphogenetic protein-2 (BMP-2), decreasing their utility in the evaluation of chondrogenic process in vitro.

Cells differentiated in the conditioned medium were demonstrated to present features that were characteristic of mature chondrocytes. In contrast, cells cultured in the presence of TGF- $\beta 3$ presented characteristics of hypertrophic chondrocytes, which may result in a decreased capacity to repair and regenerate articular cartilage and impaired viscoelastic properties compared with normal chondrocytes. Consequently, the HC-402-05a-conditioned medium offers greater potential for in vitro chondrogenesis. The present study contributes to an improved understanding of the changes in gene expression during the in vitro chondrogenic process and the short-term culture of stem-derived chondrocytes, in addition to clarifying the relative value of a wide range of chondrogenic differentiation markers.

This is a two-part study. The first part of the study (14) described markers characteristic for the pluripotent state and early and advanced stage chondrogenesis. Part B, presented here, focuses on markers that are characteristic of late stage chondrogenesis, hypertrophy, and ossification (Table I).

\section{Materials and methods}

Culturing human induced pluripotent stem cells. The hiPSCs obtained during the reprogramming process as previously described (15) were seeded on $10 \mathrm{~cm}$ Petri dishes in Matrigel (BD Biosciences, Franklin Lakes, NJ, USA) which had previously been coated with inactivated murine embryonic fibroblasts as a feeder layer $\left(1 \times 10^{6}\right)$. Following $24 \mathrm{~h}$ preparation of the feeder layer, hiPSCs were seeded at $2 \times 10^{6}$ in hiPSC growth medium: Dulbecco's modified Eagle's medium (DMEM) F12 with L-glutamine (Merck Millipore, Darmstadt, Germany), 20\% knockout serum replacement (Thermo Fisher Scientific, Inc., Waltham, MA, USA), $1 \%$ non-essential amino acids (Merck Millipore), $0.1 \mathrm{mM} \beta$-mercaptoethanol (Merck Millipore), $1 \%$ penicillin/streptomycin (P/S; Merck Millipore). Prior to use, the medium was supplemented with fibroblast growth factor 2 (FGF-2; $10 \mathrm{ng} / \mathrm{ml}$; Merck Millipore). The complete hiPSC growth medium was supplemented with ciprofloxacin $(0.5 \mu \mathrm{g} / \mathrm{ml}$; Sigma Aldrich; Merck Millipore) to avoid Mycoplasma spp. contamination for the first 7 days of culture. The culture medium was changed daily.

EB formation. At $80 \%$ confluency, hiPSC colonies were passaged and dissociated into clumps with $0.1 \%$ collagenase IV solution (Thermo Fisher Scientific, Inc.). The cells were centrifuged ( $300 \times \mathrm{g}, 5 \mathrm{~min}$, room temperature) in order to remove the collagenase and transferred into non-adherent 96-well plates (1,000 cells per well; Brand $\mathrm{GmbH}$, Wertheim, Germany) in EB growth medium, which is a hiPSC growth medium without FGF-2. EBs formed within $24 \mathrm{~h}$ and were observed as free-floating aggregates. The culture medium was changed every 48 h. On day 7 the EBs were used for chondrogenic differentiation.

Chondrogenesis in vitro. A standard chondrogenic medium was used: DMEM F12 with L-glutamine (Merck Millipore), $10 \%$ fetal bovine serum (FBS; Biowest, Nuaillé, France), $50 \mu \mathrm{M}$ L-proline (Sigma Aldrich; Merck Millipore), $50 \mu \mathrm{M}$ ascorbic acid (Sigma Aldrich; Merck Millipore), 1 mM sodium pyruvate (Biowest), 1\% ITS + Premix (Corning Life Sciences, Big Flats, NY, USA), $1 \%$ P/S (Merck Millipore) and $10^{-7} \mathrm{M}$ dexamethasone (Sigma Aldrich; Merck Millipore). 
Table I. Analysis of the usefulness of selected markers for advanced hiPSC chondrogenic differentiation in vitro.

\begin{tabular}{|c|c|c|c|}
\hline Marker & $\begin{array}{l}\text { Function of marker } \\
\text { (stage of presentation) }\end{array}$ & $\begin{array}{c}\text { Influence on } \\
\text { chondrogenesis: } \\
\text { Positive }(+) \text { or } \\
\text { negative (-) }\end{array}$ & $\begin{array}{c}\text { The usefulness } \\
\text { of marker in } \\
\text { evaluation of } \\
\text { chondrogenic } \\
\text { progression } \\
(+,++,+++)\end{array}$ \\
\hline $\begin{array}{l}\text { TGF- } \beta \text { IR, TGF- } \beta \text { IIR, } \\
\text { TGF- } \beta \text { IIIR, }\end{array}$ & Pluripotency, chondrogenesis, ossification, osteoarthritis & $-/+$ & + \\
\hline TGF- $\beta 2,-\beta 3$ & Chondrocytes/hypertrophic chondrocytes/osteoblasts & + & ++ \\
\hline BMP-2, BMP-4 & Chondrocytes/hypertrophic chondrocytes/osteoblasts & + & ++ \\
\hline GDF-5 & Chondrocytes/hypertrophic chondrocytes/osteoblasts & + & ++ \\
\hline SMAD3 & Chondrocytes & + & ++ \\
\hline TYPE I COLLAGEN & Dedifferentiated chondrocytes & - & ++ \\
\hline TYPE II COLLAGEN & Chondroprogenitors/mature chondrocytes & + & ++ \\
\hline TYPE X COLLAGEN & Hypertrophic chondrocytes/endochondral ossification & - & ++ \\
\hline TYPE XI COLLAGEN & Mature chondrocytes & + & ++ \\
\hline $\mathrm{IHH}$ & Hypertrophic chondrocytes & + & ++ \\
\hline PTHLH & Chondrocytes-prevents from hypertrophy & - & ++ \\
\hline PTCH1 & Proliferating/hypertrophic chondrocytes & $-/+$ & ++ \\
\hline RUNX2 & Chondrocytes/hypertrophic chondrocytes/osteoblasts & - & ++ \\
\hline CH13L1 & OA chondrocytes & - & +++ \\
\hline MMP-2 & Chondrocytes & + & ++ \\
\hline MMP-13 & $\begin{array}{l}\text { Hypertrophic chondrocytes/OA chondrocytes/ } \\
\text { endochondral bone formation }\end{array}$ & - & ++ \\
\hline ALPL & $\begin{array}{l}\text { Maintenance of pluripotency/hypertrophic chondrocytes/ } \\
\text { OA chondrocytes }\end{array}$ & - & + \\
\hline VEGF & Angiogenesis & - & +++ \\
\hline
\end{tabular}

The number of plus symbols $(+,++,+++)$ indicates the utility of the marker, as follows: Average (+), good (++), very good (+++). TGF- $\beta$ IR, transforming growth factor $\beta$ I receptor; BMP, bone morphogenetic protein; GDF-5, growth differentiation factor 5; IHH, indian hedgehog; PTHLH, parathyroid hormone-like hormone; RUNX2, runt-related transcription factor 2; CH13L1, chitanise-3-like protein; MMP, matrix metalloproteinase; ALPL, alkaline phosphatase; VEGF, vascular endothelial growth factor.

Medium conditioning. Standard chondrogenic medium was used: DMEM F12 with L-glutamine (Merck Millipore), 10\% FBS (Biowest), $50 \mu \mathrm{M}$ L-proline (Sigma Aldrich; Merck Millipore), $50 \mu \mathrm{M}$ ascorbic acid (Sigma Aldrich; Merck Millipore), $1 \mathrm{mM}$ sodium pyruvate (Biowest), $1 \%$ ITS + Premix (Corning, Life Sciences), 1\% P/S (Merck Millipore) and $10^{-7} \mathrm{M}$ dexamethasone (Sigma Aldrich; Merck Millipore), which was conditioned on the HC-402-05a cell line (up to 3 passages). Medium was collected following $24 \mathrm{~h}$ conditioning and administered to the differentiated EBs.

Chondrogenesis using EBs. The mature EBs were transferred onto 6-well plates (10 EBs per well) previously coated with $0.1 \%$ gelatin (Merck Millipore) and allowed to adhere for the next $24 \mathrm{~h}$, following which the medium was replaced with a chondrogenic medium This was either supplemented with TGF- $\beta 3$ (10 ng/ml; ImmunoTools GmbH, Friesoythe, Germany), as a growth factor with the most chondrogenic potential, or conditioned with the HC-402-05a cell line as above. The positive influence of standard chondrogenic medium with the addition of exogenous TGF- $\beta 3(10 \mathrm{ng} / \mathrm{ml})$ on pluripotent stem cells was previously tested and confirmed by our group (16). The chondrogenic medium was changed every $48 \mathrm{~h}$. The culture period lasted 21 days. In order to confirm that chondrocyte-like cells had been obtained, immunofluorescence analysis was performed on passage 0 (p0). Subsequently, to evaluate the expression profile of chondrogenic markers (p3), reverse transcription-quantitative polymerase chain reaction (RT-qPCR) analysis was performed (14). In all analyses, the stable adult human articular chondrocyte cell line (HC-402-05a) served as a positive control, as the European Collection of Authenticated Cell Cultures recommended it for the evaluation of the differentiation process in in vitro model systems.

Culture of differentiated cells. The derived stem cells were cultured in $0.1 \%$ gelatin (Merck Millipore) in DMEM F12 with L-glutamine (Merck Millipore), 10\% FBS (Biowest), and $1 \% \mathrm{P} / \mathrm{S}$ (Merck Millipore) up to 3 passages.

$R T-q P C R$. Total RNA was extracted from cells (p3; $2 \times 10^{6}$ cells) with TRIzol (Sigma Aldrich; Merck Millipore). Total RNA 
(1 $\mu \mathrm{g}$ per $20 \mu \mathrm{l}$ reaction volume) free of genomic DNA contamination was reverse-transcribed using the iScript $^{\mathrm{TM}}$ cDNA Synthesis kit (Bio-Rad Laboratories, Inc., Hercules, CA, USA) according to the manufacturer's protocol $\left(25^{\circ} \mathrm{C}\right.$ for $5 \mathrm{~min}, 42^{\circ} \mathrm{C}$ for $30 \mathrm{~min}, 85^{\circ} \mathrm{C}$ for $\left.5 \mathrm{~min}\right)$. qPCR reactions were performed using the LightCycler 480 Probes Master mix and appropriate probes labeled with fluorescein for each primer (Roche Diagnostics, Basel, Switzerland). The reaction conditions for all amplicons were as follows: Initially $95^{\circ} \mathrm{C}$ for $10 \mathrm{~min}$, followed by 45 cycles at $94^{\circ} \mathrm{C}$ for $10 \mathrm{sec}, 60^{\circ} \mathrm{C}$ for $15 \mathrm{sec}$ and $72^{\circ} \mathrm{C}$ for $1 \mathrm{sec}$. All reactions were performed in the presence of $3.2 \mathrm{mM} \mathrm{MgCl} 2$. cDNA samples $(2.5 \mu \mathrm{l}$ for a total volume of $10 \mu \mathrm{l}$ ) were analyzed for genes of interest and for the reference gene glyceraldehyde 3-phosphate dehydrogenase, which were selected based on the latest literature data concerning chondrogenic differentiation of hiPSCs (17). The level of expression of each target gene was calculated as $-2^{\Delta \Delta \mathrm{Cq}}(18)$. The reaction was performed in triplicate for genes of interest: TGF- $\beta$ receptor 1 (TGF- $\beta I R), T G F-\beta I I R$, TGF- $\beta I I I R, T G F-\beta 2, T G F-\beta 3, B M P-2, B M P-4$, growth differentiation factor $5(G D F-5)$, SMAD3, type I collagen, type II collagen, type XI collagen, Indian hedgehog $(I H H)$, parathyroid hormone-like hormone $(P T H L H)$, patched 1 (PTCH1), RUNX2, chitanise-3-like protein ( $\mathrm{CH} 13 \mathrm{L1})$, matrix metalloproteinase $2(M M P-2), M M P-13$, alkaline phosphatase $(A L P L), V E G F$. Primer information is available upon request.

Statistical analysis. All experiments were performed a minimum of three times. The results are reported as the mean \pm standard deviation. Comparisons between the study groups and controls were performed using one-way analysis of variance. Where the analysis of variance results were significant, post hoc analysis was performed via Tukey's multiple comparison test with a single pooled variance. Statistical tests were performed with GraphPad Prism (version 5.0a; GraphPad Software, Inc., San Diego, CA, USA). 'P<0.05 was considered to indicate a statistically significant difference.

\section{Results}

Gene expression profiles of stem cell-derived chondrocytes revealed the presence of receptors and members of TGF- $\beta$ superfamily. Immunofluorescence analysis confirmed that chondrocyte-like cells were obtained (14). The presence of the following TGF- $\beta$ receptors in the cultured cells was determined: TGF- $\beta R I, T G F-\beta R I I$, and TGF- $\beta R I I I$. The presence of members of the TGF- $\beta$ superfamily was also observed, as follows: $T G F-\beta 2, T G F-\beta 3, B M P-2, B M P-4$, and $G D F-5$.

$T G F-\beta R I$ was expressed by all the cells, but most prominently by cells differentiated in TGF- $\beta 3$ medium and by PHDFs (Fig. 1). TGF- $\beta$ RII was also expressed by all cells, but was most prominent in cells differentiated in in conditioned medium, HC-402-05a cells and PHDFs (Fig. 1). TGF- $\beta$ RIII was highly expressed by HC-402-05a cells and PHDFs (Fig. 1). TGF- $\beta 2$ expression was also observed at relatively low levels in HC-402-05a cells and in cells differentiated in the conditioned medium, but cells differentiated in the TGF- $\beta 3$ medium demonstrated relatively high expression (Fig. 2). TGF- $\beta 3$ was only present, at similar levels, in the two types of chondrocyte-like cells differentiated in vitro (Fig. 2).
$B M P-2$ was expressed by all cells, but its expression level was highest in PHDFs (Fig. 2). BMP-4 was also expressed by all cells, with the highest levels of expression observed in the positive-control HC-402-05a cells. Among the differentiated cells, BMP-4 expression was higher in those cultured in the presence of TGF- $\beta 3$ (Fig. 2).

GDF-5 mRNA was present in all cells, with the highest levels of expression in HC-402-05a cells and similar levels of expression in the two differentiated cell groups (Fig. 3). SMAD3 expression was observed in all cells, with the highest level of expression in cells differentiated in the presence of TGF- $\beta 3$ (Fig. 3).

Collagen expression. Type I collagen was expressed primarily by PHDFs, but was also detectable in HC-402-05a cells, the two hiPSC-derived chondrocyte groups, and at very low levels in hiPSCs (Fig. 4). No expression of type II collagen was observed. Expression of type $X$ collagen in PHDFs was relatively high compared with the other cell groups (Fig. 4). Cells differentiated in HC-402-05a or TGF- $\beta 3$ medium presented with a higher production of type $X$ collagen at the mRNA level compared with positive control HC-402-05a cells (Fig. 4). Type XI collagen was most highly expressed by cells obtained by TGF- $\beta 3$-mediated chondrogenesis and, to a lesser extent, by HC-402-05a (Fig. 4).

Markers of hypertrophy. Expression of $I H H$ was detectable in all examined cells, with the highest levels observed in the cells differentiated with HC-402-05a-conditioned medium (Fig. 5). mRNA transcripts of PTHLH were most abundant in PHDFs, followed by the chondrocyte-like cells obtained in the TGF- $\beta 3$ medium (Fig. 5). All cells expressed PTCH1, and in decreasing order $\mathrm{PTCH}$ l expression was highest in hiPSCs, cells differentiated in the presence of TGF- $\beta 3$, PHDFs, HC-402-05a cells, and cells differentiated in the conditioned medium (Fig. 5). RUNX2 was expressed most highly in cells obtained via TGF- $\beta 3$-mediated chondrogenesis, but was also present in PHDFS and hiPSCs. By contrast, this marker was not present in cells cultured in the conditioned medium (Fig. 5).

Markers associated with osteoarthritis and ossification. Only the HC-402-05a cell line expressed CH13L1 (Fig. 6). According to a previously published study (19) this marker is present in chondrocytes cultured in vitro. This mRNA was not observed in the differentiated cells, which suggests a lack of inflammatory properties in stem cell-derived chondrocyte cultures. In addition, the specificity of CH13L1 was demonstrated. All differentiated cells expressed $M M P-2$ (Fig. 6). The presence of $M M P-2$ is likely to be correlated with extracellular matrix (ECM) remodelling that occurs during chondrogenesis, including the reduction of the matrix protein content. However, cells differentiated in the presence of TGF- $\beta 3$ expressed $M M P-2$ and also $M M P-13$, and this presence in chondrocyte-like cells differentiated from hiPSCs and chondrocytes is undesirable (Fig. 6). This observation demonstrated that these cells were derived from late stage chondrogenesis. Due to the capacity of $M M P-13$ to degrade chondrogenic proteins, its high mRNA expression levels and potential high levels of its protein product may explain the 
TGFBIR

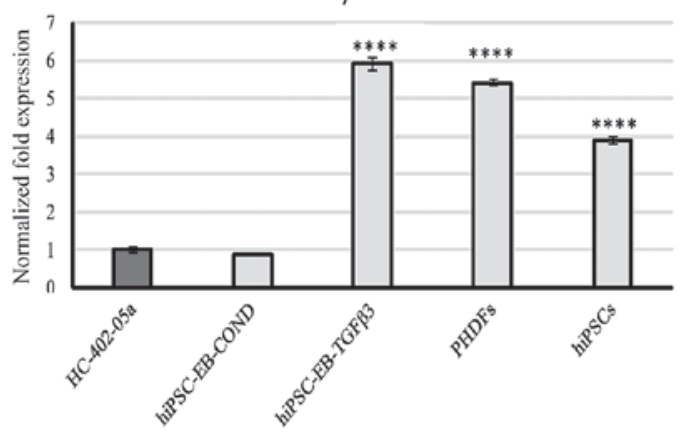

TGFBIIR

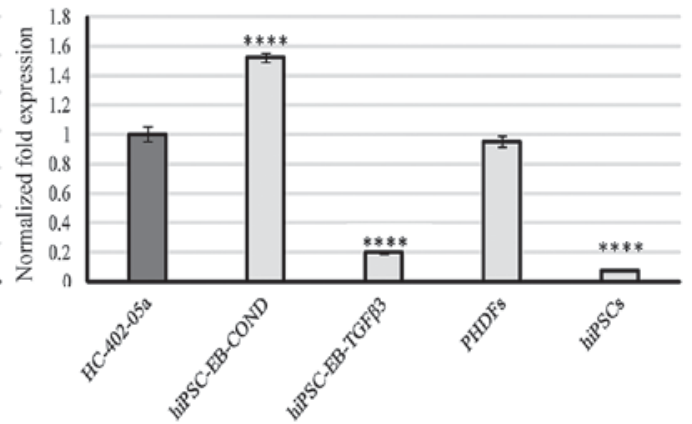

TGFBIIIR

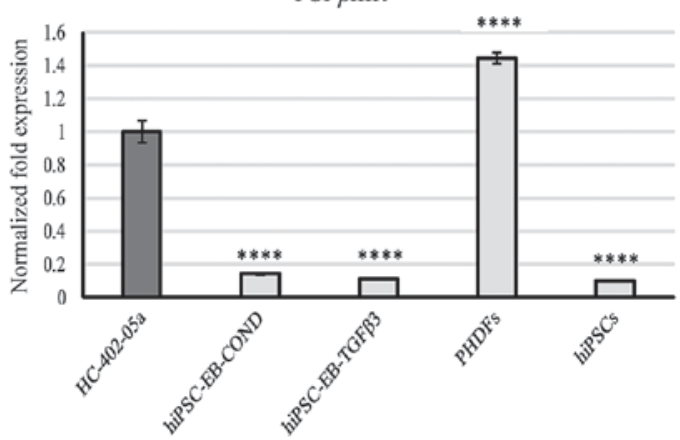

Figure 1. The hiPSC-derived chondrocytes differentiated in chondrogenic medium with TGF- $\beta 3$ (10 ng/ml) or following conditioning on HC-402-05a cells indicated the presence of mRNA characteristic for TGF- $\beta$ IR, TGF- $\beta$ IIR and TGF- $\beta$ IIIR. The HC-402-05a cell line served as a positive control. PHDFs and hiPSCs were used as negative controls. ${ }^{* * * *} \mathrm{P}<0.0001$ vs. HC-402-05a. hiPSCs, human induced pluripotent stem cells; TGF- $\beta 3$, transforming growth factor $\beta 3$; TGF- $\beta$ IR, TGF- $\beta$ type I receptor; TGF- $\beta$ IIR, TGF- $\beta$ type II receptor; TGF- $\beta$ IIIR, TGF- $\beta$ type III receptor; PHDFs, primary human dermal fibroblasts; EB, embryoid bodies, COND, conditioned medium.
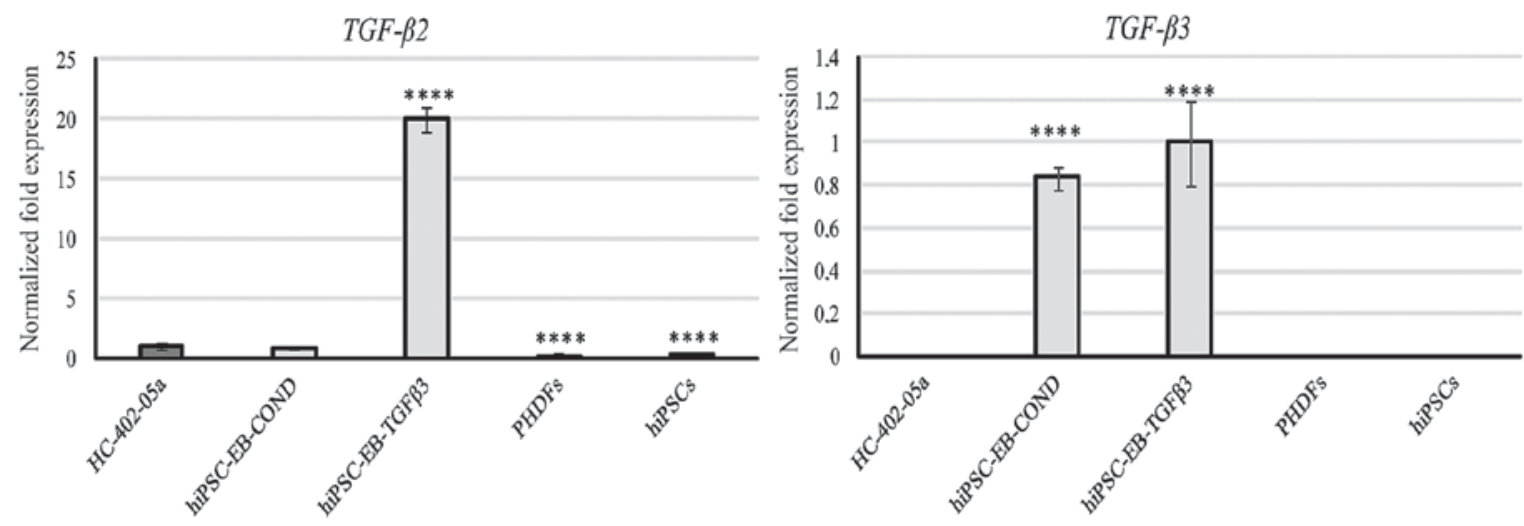

$B M P-2$
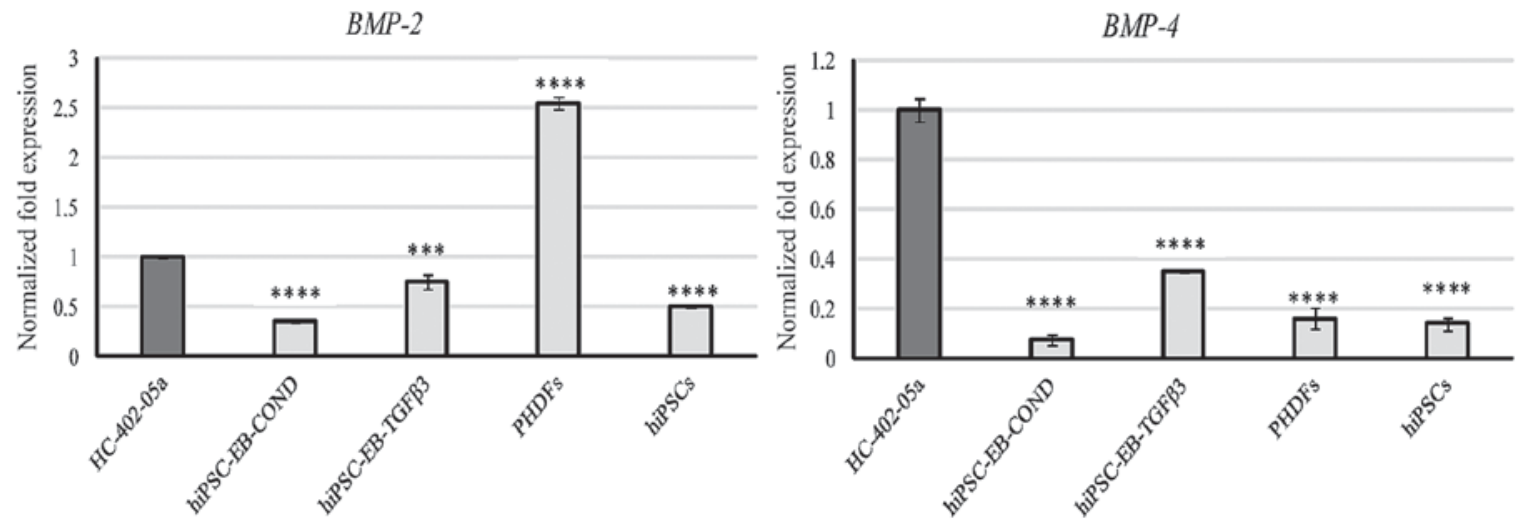

Figure 2. The chondrocyte-like cells obtained following differentiation in chondrogenic medium with TGF- $\beta 3$ (10 ng/ml) or on medium conditioned with HC-402-05a cells demonstrated expression of members of the TGF- $\beta$ superfamily: TGF- $\beta 2$, TGF- $\beta 3$, BMP-2 and BMP-4. The HC-402-05a cell line served as a positive control. PHDFs and hiPSCs were used as negative controls. ${ }^{* * * *} \mathrm{P}<0.0001$ vs. HC-402-05a. TGF- $\beta$, transforming growth factor $\beta$; BMP-2, bone morphogenetic protein-2; BMP-4, bone morphogenetic protein-4; PHDFs, primary human dermal fibroblasts; hiPSCs, human induced pluripotent stem cells; EB, embryoid bodies, COND, conditioned medium. 
GDF-5

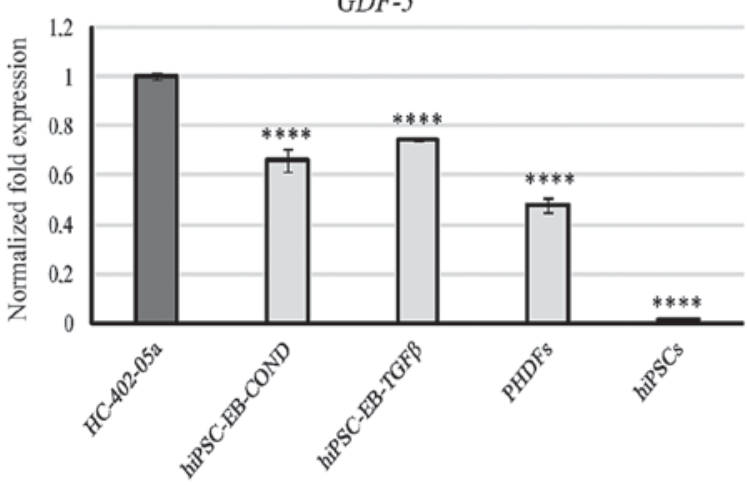

SMAD3

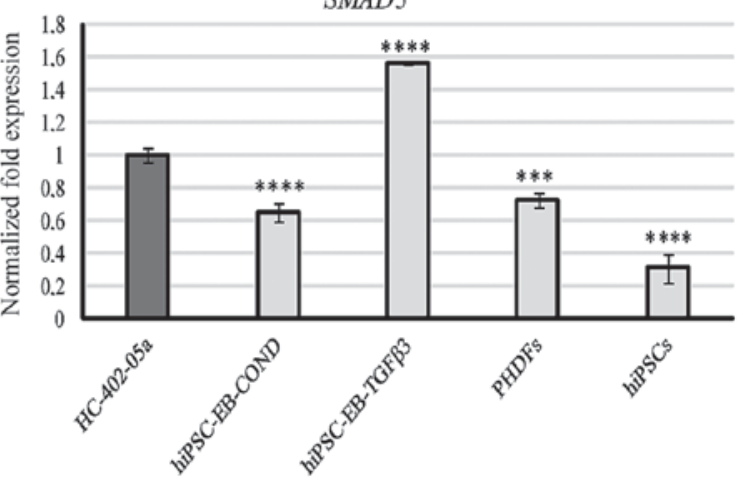

Figure 3. The chondrocyte-like cells obtained following differentiation in chondrogenic medium with TGF- $\beta 3$ (10 ng/ml) or on medium conditioned with HC-402-05a cells demonstrated expression of GDF-5 and SMAD3 at the mRNA level. The HC-402-05a cell line served as a positive control. PHDFs and hiPSCs were used as negative controls. ${ }^{* * * *} \mathrm{P}<0.001,{ }^{* * * *} \mathrm{P}<0.0001$ vs. HC-402-05a. TGF- $\beta 3$, transforming growth factor $\beta 3$; GDF-5, growth differentiation factor 5; SMAD3, SMAD family member 3; PHDFs, primary human dermal fibroblasts; hiPSCs, human induced pluripotent stem cells; EB, embryoid bodies; COND, conditioned medium.
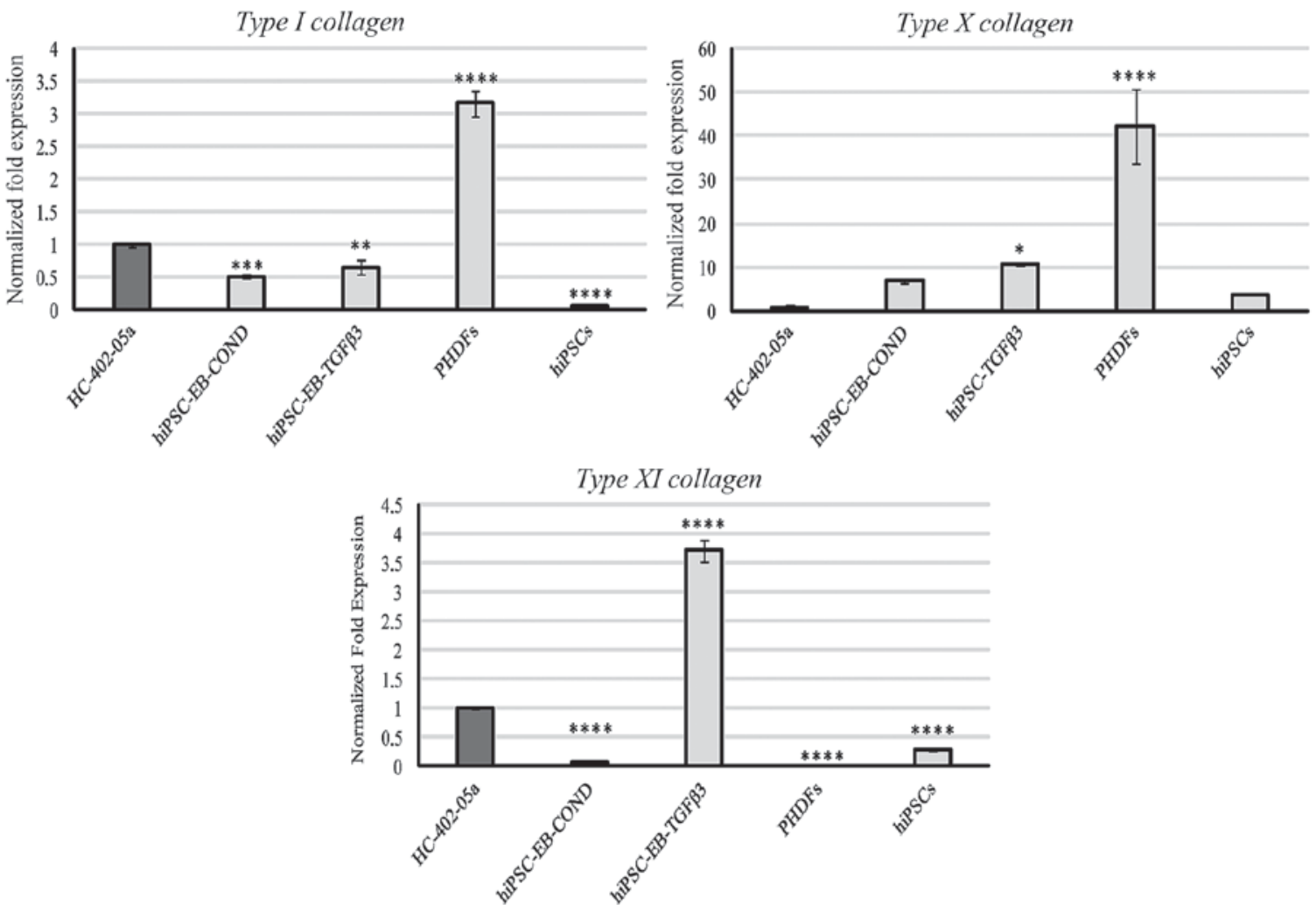

Figure 4. Type II collagen was not expressed by the examined cells. However, the chondrocyte-like cells obtained following differentiation in chondrogenic medium with TGF- $\beta 3(10 \mathrm{ng} / \mathrm{ml})$ or on medium conditioned with HC-402-05a cells demonstrated expression of type I, X and XI collagen characteristic of dedifferentiated, hypertrophic and mature chondrocytes, respectively. The HC-402-05a cell line served as a positive control. ${ }^{* *} \mathrm{P}<0.05,{ }^{* * *} \mathrm{P}<0.01,{ }^{, * * *} \mathrm{P}<0.001$, ${ }^{* * * * *} \mathrm{P}<0.0001$ vs. HC-402-05a. PHDFs and hiPSCs were used as negative controls. TGF- $\beta 3$, transforming growth factor $\beta 3$; PHDFs, primary human dermal fibroblasts; hiPSCs, human induced pluripotent stem cells; EB, embryoid bodies; COND, conditioned medium.

loss of proteoglycans including type II and X collagen and aggrecan.

Finally, cells differentiated in the TGF- $\beta 3$ medium demonstrated relatively minor expression of $A L P L$ (Fig. 6). These results are consistent with other data obtained in the present study (including $R U N X 2$; Fig. 5), confirming that cells differentiated in the TGF- $\beta 3$ medium presented with a hypertrophic phenotype. The highest levels of $A L P L$ were detectable in negative control hiPSCs, underscoring their pluripotent properties. None of the cells in the present study expressed $V E G F$, a finding that suggested that differentiated cells, regardless of medium preparation, did not undergo vascularization following endochondral ossification.

\section{Discussion}

In the present study, hiPSC cells were differentiated in two different mediums: One supplemented with TGF- $\beta 3$ and the 

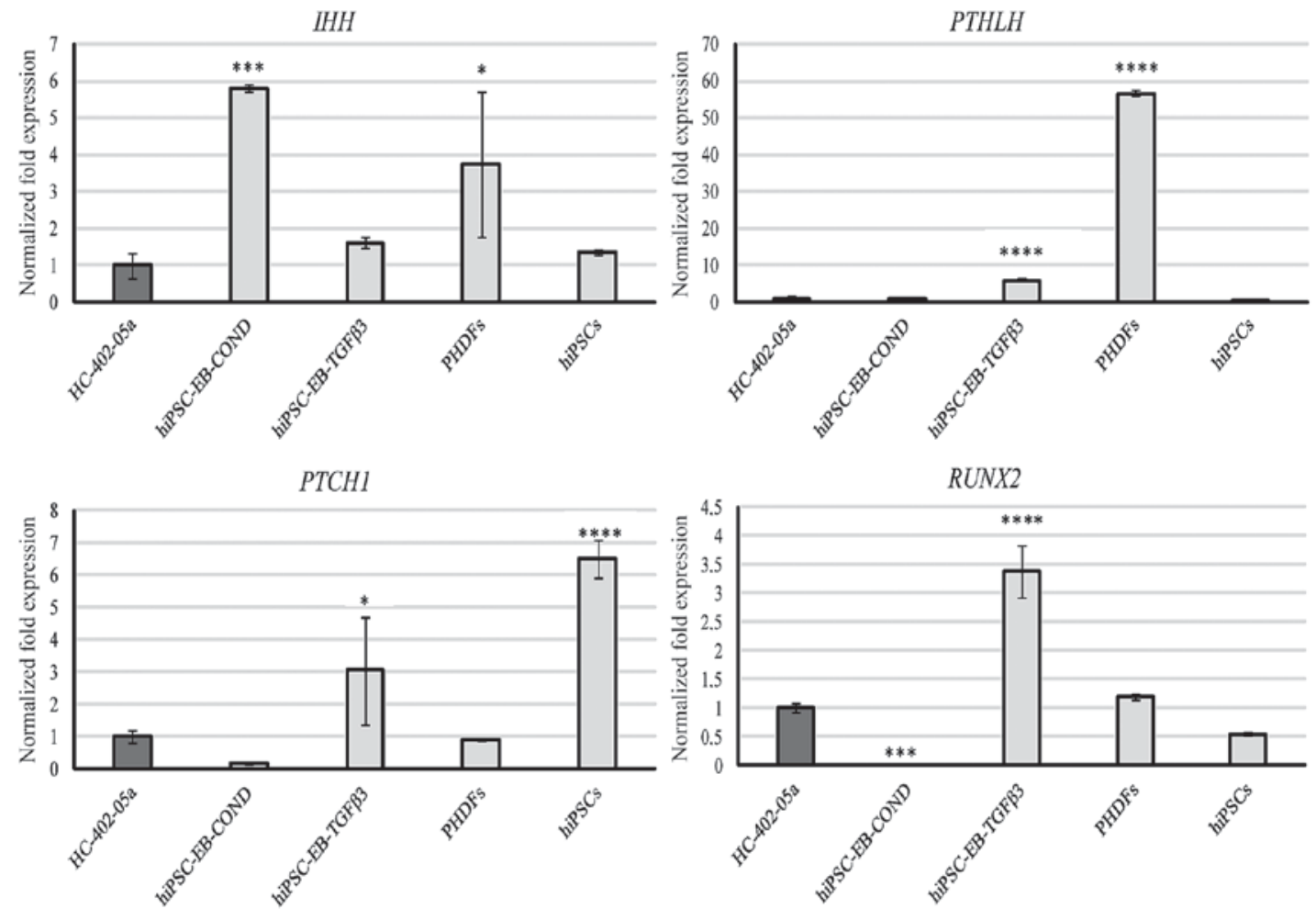

Figure 5. The chondrocyte-like cells obtained following differentiation in chondrogenic medium with TGF- $\beta 3$ (10 ng/ml) or on medium conditioned with HC-402-05a cells expressed genes from late chondrogenesis and hypertrophic chondrocytes: IHH, PTHLH, PTCH1 and RUNX2. The HC-402-05a cell line served as a positive control. PHDFs and hiPSCs were used as negative controls. ${ }^{*} \mathrm{P}<0.05,{ }^{* * * *} \mathrm{P}<0.001,{ }^{* * * * *} \mathrm{P}<0.0001$ vs. HC-402-05a. TGF- $\beta 3$, transforming growth factor $\beta 3$; IHH, Indian hedgehog; PTHLH, parathyroid hormone- like hormone; PTCH1, patched 1; RUNX2, runt-related transcription factor 2; PHDFs, primary human dermal fibroblasts; hiPSCs, human induced pluripotent stem cells; EB, embryoid bodies; COND, conditioned medium.
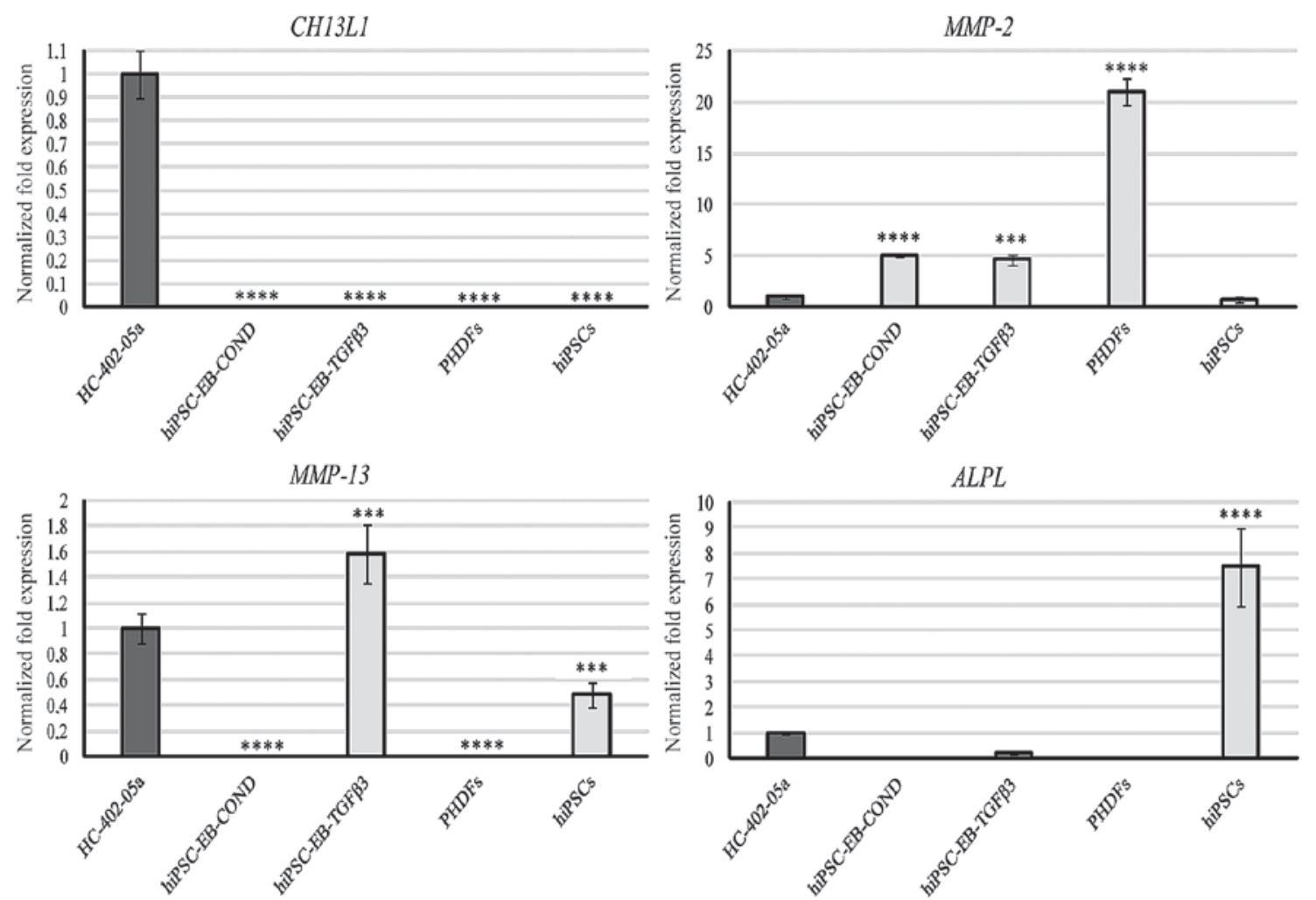

Figure 6. The hiPSC-derived chondrocytes obtained via differentiation in chondrogenic medium with TGF- $\beta 3$ (10 ng/ml), in contrast to those differentiated in chondrogenic medium medium conditioned with HC-402-05a cells, possessed undesirable markers characteristic of mature and osteoarthritic chondrocytes: Ch13L1, MMP-2, MMP-13 and ALPL. The HC-402-05a cell line served as a positive control. PHDFs and hiPSCs were used as negative controls. ${ }^{* * *} \mathrm{P}<0.001$, ${ }^{* * * * *} \mathrm{P}<0.0001$ vs. HC-402-05a. hiPSCs, human induced pluripotent stem cells; TGF- $\beta 3$, transforming growth factor $\beta 3$; Ch13L1, chitanise-3-like protein; MMP, matrix metalloproteinase; ALPL, alkaline phosphatase; PHDFs, primary human dermal fibroblasts; EB, embryoid bodies; COND, conditioned medium. 
other conditioned with growth factors from HC-402-05a cells. Notably, differentiation in the conditioned medium resulted in greater chondrogenesis of the hiPSCs. On the other hand, cells cultured in the presence of TGF- $\beta 3$ presented with characteristics shared with hypertrophic chondrocytes, which may result in their decreased capacity to repair and regenerate articular cartilage. Thus, the HC-402-05a-conditioned medium offers greater potential for in vitro chondrogenesis. The differentiated cells were then evaluated using 22 different chondrogenic markers to assess the progression of chondrogenic differentiation, as well as to determine the relative value of these markers in predicting chondrogenic differentiation. Furthermore, chondrogenic properties were demonstrated to change even during short-term culture (passage 0 vs. 3 ). The aim in doing so was to identify the best markers of late stage chondrogenesis, hypertrophy and ossification. The most promising gene markers of hiPSC differentiation during late stage chondrogenesis were TGF- $\beta 2, T G F-\beta 3$, type XI collagen and PTHLH. The best markers during hypertrophy were $R U N X 2, I H H$ and type $\mathrm{X}$ collagen, and during ossification $M M P-13$ and $V E G F$ were good markers. VEGF expression was specific to old and overgrown chondrocytes only (data not shown). Useful however less valuable markers included TGF- $\beta$ receptors and the remaining members of the TGF- $\beta$ superfamily (Table I).

TGF- $\beta$ receptors are engaged in multiple cellular processes. The TGF- $\beta$ family of receptors forms a functional complex on the cell surface, which consists of type II and type I transmembrane serine/threonine kinase receptors. TGF- $\beta 1$ and TGF- $\beta 3$ bind to their type II receptors while BMP-2 and BMP-4 bind primarily to type I receptors. Activation of the epidermal growth factor receptor inhibits TGF- $\beta$ signaling (20). TGF- $\beta$ molecules exert their effects on cells by binding to the TGF- $\beta$ receptors. The TGF- $\beta$ type II receptor (T $\beta$ RII) recruits and interacts with T $\beta$ RI through multiple parallel signaling pathways, including SMAD proteins. T $\beta$ RIII acts as a co-receptor, increasing the binding rate of ligands to T $\beta$ RII. T $\beta$ RII and T $\beta$ RIII are present in fibroblast cells, but are downregulated in fibroblasts and myofibroblasts in patients with oral squamous cell carcinoma or oral carcinoma $(20,21)$. According to Keller et al (22), TRRI is expressed in proliferating but not hypertrophic chondrocytes. These same authors also demonstrated the negative regulation of BMP- 2 in TGF- $\beta$ signaling and revealed that exogenous or upregulated TGF- $\beta 1$ significantly increases BMP signaling (22). However, it is important to note that this negative regulation does not fully agree with previously published data and must therefore be further validated (23).

SMAD2 and 3 respond to TGF- $\beta$ receptors. In response to activation of TGF- $\beta$, the SMAD and p38 mitogen activated protein kinase (MAPK) pathways, together with the RUNX2 gene, control mesenchymal precursor cell differentiation. Induction of TGF- $\beta$ /BMP-2 signaling, MAPK-dependent phosphorylation and $R U N X 2$ results in osteoblast differentiation (24). The TGF- $\beta$ isoforms and TGF- $\beta$ receptors are expressed in cartilage, bone and synovial tissues. In osteoarthritis, there is an interaction between TGF- $\beta$ signaling (in particular between $R U N X 2$ and $M M P-13$ ) and WNT/ $\beta$-catenin and Notch, as well as IHH (25). TGF- $\beta$ family signaling occurs not only in differentiation but also in maintenance of self-renewal and pluripotency of hESCs, due to the interplay between TGF- $\beta$, activin, and Nodal signaling, whose activity significantly decreases during early differentiation (26).

Cells differentiated in TGF- $\beta 3$ and HC-402-05a conditioned mediums expressed $T G F-\beta$ receptors $I, I I$ and $I I I$. Nevertheless, the profiles of expression varied according to the culture medium: Cells differentiated in the conditioned medium presented with a greater expression of $T \beta R I I$ whereas cells cultured in the TGF- $\beta 3$-medium demonstrated higher expression of $T \beta R I$ (Fig. 1). In this case the usage of sequential administration of growth factors is likely to be an interesting approach in effective chondrogenesis of stem cells in vitro. The available evidence indicates that $T G F-\beta$ receptors are not specific markers of in vitro chondrogenesis because these receptors are engaged in multiple processes during several stages of development, including maintenance of pluripotency, chondrogenesis and ossification, and also in disease conditions including osteoarthritis (27). The results of the present study confirm this characteristic: The TGF- $\beta$ receptors were expressed by numerous cell types, including all differentiated cells, PHDFs, HC-402-05a, and hiPSCs (Fig. 1). This lack of specificity makes them unsuitable as markers for chondrogenic differentiation.

The TGF- $\beta$ superfamily is involved in regulating chondrogenesis and is composed of two subfamilies: The TGF- $\beta$ subfamily (TGF- $\beta 1$, TGF- $\beta 2$, TGF- $\beta 3$, activin, nodals, myostatin, and Mullerian inhibiting substance) and the BMP subfamily (BMP-2, BMP-4, BMP-10, GDFs) (28). TGF- $\beta 1$ and $T G F-\beta 3$ are highly expressed in the proliferative and hypertrophic zones. $T G F-\beta 2$ expression is observed in all zones, particularly the hypertrophic zone. Although TGF- $\beta 1$ induces chondrogenesis, TGF- $\beta 2$ and TGF- $\beta 3$ are even more chondrogenic, resulting in a two-fold greater production of glycosaminoglycan (28). Tan et al (29) reported that inhibition of TGF- $\beta$ signaling through addition of the SB431542 molecule may substitute for octamer-binding transcription factor 3/4 in generating PSCs. Those authors also demonstrated that mPSCs with an inhibited TGF- $\beta$ signaling pathway had greater pluripotent properties due to a decrease in extracellular signal-related kinase (ERK) phosphorylation and consequent modulation of FGF/ mitogen-activated protein kinase kinase/ERK signaling (29). Overexpression of TGF- $\beta$ during enhanced cartilage repair, apart from the accumulation of proteoglycans, may lead to synovial fibrosis. The intercellular signaling molecule SMAD7 inhibits SMAD2 and SMAD3 phosphorylation, thereby further blocking the TGF- $\beta$ signaling pathway. The simultaneous overexpression of $T G F-\beta$ and SMAD7 prevents TGF- $\beta$-induced fibrosis by maintaining the repair-stimulating effect of TGF- $\beta$ on cartilage (30). Tekari et al (31) expanded chondrocytes in a monolayer culture and reported that the chondrocytes maintained their potential for cartilage-like tissue formation for up to three passages. However, exogenous TGF- $\beta 1$ had to be added following three passages to induce the formation of cartilage-like tissue. The authors hypothesized that this may be due to the lower expression of $T G F-\beta$ family members and $T G F-\beta$ receptors during prolonged culture (31). The members of the TGF- $\beta$ subfamily additionally possess osteogenic potential, as reported by Li et al (32), who demonstrated that miPSC-derived mesenchymal precursors differentiated into functional osteoblasts 
following stimulation with TGF- $\beta 1$ or $-\beta 3$ in the presence of retinoic acid.

In the present study, cells differentiated in the conditioned medium expressed $T G F-\beta 3$ at high levels but $T G F-\beta 2$ at lower levels. This result may indicate that these cells possess desirable chondrogenic features at the mRNA level. Cells differentiated in the presence of TGF- $\beta 3$ also expressed of $T G F-\beta 2$ and $T G F-\beta 3$ (Fig. 2). According to previously published data (32), the expression profile of these cells is characteristic of chondrocytes in the hypertrophic zone. For this reason, it is important to administer TGF- $\beta 3$ at an optimized concentration and culture period to obtain chondrocyte-like cells from early or advanced stages of chondrogenesis, thus avoiding hypertrophy during in vitro chondrogenesis. These findings revealed that expression of $T G F-\beta$ family members provides a good, specific marker of chondrogenic progression. However, because TGF- $\beta$ s are active during the entire chondrogenic and osteogenic processes, it is very difficult to classify the differentiating cells into the precise stage. Notably, the presence of TGF- $\beta s$ is observed in human chondrocytes and chondrocyte-like cells but not in parental stem cells and PHDFs, a finding that further underscores the selective nature and value of these as markers.

BMP-2 is one of the predominant growth factors with beneficial potential in cartilage repair and cartilage tissue engineering. It has the capacity to stimulate proteoglycan synthesis and enhance production of type II collagen. BMP-2 expression is elevated in areas surrounding cartilage injury and in osteoarthritis (33). $B M P-2$ and $B M P-4$ induce the progression of chondrocyte hypertrophy. Thus, increased expression of $B M P-2$ and/or $B M P-4$ is detectable during chondrocyte proliferation and maturation to endochondral bone development. BMP-2 stimulates the expression of other hypertrophic markers including type $\mathrm{X}$ collagen through SMAD1-RUNX2 interaction at the $5^{\prime}$ promoter region in addition to $A L P L$. Shu et al (34) demonstrated that $B M P-2$ is involved in endochondral bone development, while BMP-4 is involved to a lesser extent. BMP-2 has osteogenic properties and upregulates the transcription of osteogenic genes, including type I collagen, $A L P L$, osteocalcin and bone sialoprotein. However, the SMAD signaling pathway is required for activation of osterix, another factor involved in osteoblastic differentiation. BMP-2 modulates the expression of osterix through dependent and independent RUNX2 (via msh homeobox 2) mechanisms (35).

Cells differentiated in the two study mediums expressed $B M P-2$ and 4 (Fig. 2), the expression of which indicating efficient chondrogenic differentiation and also hypertrophy. Unfortunately, this marker alone is not able to indicate which of these processes is more prevalent. Nevertheless, cells cultured in the TGF- $\beta 3$ medium are assumed to possess hypertrophic properties, and they express $B M P-2$ and 4 , $R U N X 2$, and $A L P L$ at significantly higher levels than in cells differentiated in the conditioned medium and positive controls. In addition, these markers are also expressed in PHDFs (BMP-2 and -4) and hiPSCs (BMP-2; Fig. 2). For this reason it is difficult to use these markers to assess the chondrogenic process in vitro.

GDF- 5 belongs to the TGF- $\beta$ superfamily and is involved in cartilage development and differentiation. Mutations in the GDF-5 gene often result in defects in the appendicular skeleton during development (36). The expression profile of $G D F-5$ confirms its involvement in endochondral ossification. Exposure to GDF-5 increases the expression of chondrogenic markers including type I collagen and aggrecan. However, prolonged stimulation by administration of GDF-5 results in increased transcription of type X collagen and $A L P L$, which are common indicators of chondrocyte hypertrophy and initial endochondral ossification. GDF-5 may, therefore, provide efficient regeneration of damaged bone together with other pro-osteogenic and angiogenic factors (37). In osteoblast-like cells, GDF-5 stimulates the activity of gelatinases and matrix metalloproteinases (MMP-2, MMP-9 and MMP-13) at matrix formation sites. The metalloproteinases degrade denatured and native collagens (gelatin and type I collagen, respectively) and proteoglycan core proteins. This phenomenon involves the activation of the p38 MAPK signaling pathway. Expression of metalloproteinases is also under control of other members of the TGF- $\beta$ superfamily, the BMPs (38).

$G D F-5$ expression in the differentiated cells was similar to that observed in adult articular chondrocytes. As with $B M P-2$ and BMP-4 expression, GDF-5 expression may indicate successful chondrogenesis and initiation of hypertrophy. Furthermore, GDF-5 is also present in PHDFs (Fig. 3). Consequently, to identify the chondrogenic stage of the cultured cells or to rule out dedifferentiation, other markers are needed. The majority of the markers evaluated in the present study indicated the presence of chondrocyte-like cells (differentiation via the conditioned medium) and chondrocyte-like hypertrophic cells (differentiation via TGF- $\beta 3$ ).

SMAD3 is another relevant member of the TGF- $\beta$ signaling pathway. The TGF- $\beta$ RI phosphorylates SMAD2 and SMAD3, together with SMAD4, form a heteromeric complex. SMAD3 associates with multiple transcription factors, including RUNX2. Furthermore, the MH2 domain of SMAD2 and SMAD3 interacts with the co-activator cAMP-response-elem ent-binding-protein-binding protein, in addition to its paralog p300, with acetyltransferase activity. SMAD2/3 is one of the TGF- $\beta$ signaling pathways, and is involved in maintaining and developing the chondrocyte phenotype. SMAD3 enhances the transcriptional activity of SOX9 and increases expression of the type II collagen gene (39). C-terminal SMAD3 has an effect on $\beta$-catenin protein in a TGF- $\beta$-dependent manner. It protects $\beta$-catenin from ubiquitin-proteasome-dependent degradation and mediates its nuclear transition. This SMAD3-mediated mechanism of $\beta$-catenin protein stability promotes the activity of $\beta$-catenin, in turn affecting its downstream target chondrogenesis-associated genes (40). SMAD3 is also responsible for the balance between cartilage matrix synthesis and degradation through increasing type II collagen expression with simultaneous inhibition of RUNX2-induced MMP-13 expression. SMAD3 maintains chondrocyte homeostasis and prevents cells from hypertrophy and osteoarthritis (41).

The expression of SMAD3 was detectable in all cells, with the highest expression in cells differentiated in the TGF-33-medium (Fig. 3). Given the elevated level of RUNX2, this may indicate that these cells started to activate their SMAD3-mediated defence mechanisms to prevent hypertrophy. As a marker of chondrogenesis, the specificity of 
SMAD3 is questionable because its expression is observed in chondrocytes, chondrocyte-like cells, and in the negative controls (PHDF and hiPSCs).

Collagens represent a highly diverse group of ECM proteins. The type II procollagen gene COL $2 A 1$ is widely expressed in non-chondrogenic and chondrogenic tissues. As a result of alternate splicing, type II collagen is synthesized and secreted into ECM as two isoforms: II1 and IIB. The II1 isoform is expressed in chondroprogenitor cells while the IIB isoform occurs in differentiated chondrocytes (42). Krug et al (43) examined the change in patterns of gene expression (type II, IX and XI collagen and aggrecan) in ESC-derived and primary chondrocytes. The chondrocytes lost their characteristic phenotype (including type II collagen and aggrecan) during monolayer culture (43). Type I collagen is a dedifferentiation marker of chondrocyte-like cells because it is widely expressed in primary human fibroblasts. It is characteristic in bone, tendon, cornea and skin. During cartilage injury or osteochondral defects, differentiation towards fibroblasts and osteoblasts producing type I collagen and fibronectin is favoured (44). Aggrecan, type X and type II collagen are markers of late stage chondrocyte hypertrophy associated with endochondral ossification. However, Mwale et al (45) advise against straightforward classification of these markers, as in certain cases type $\mathrm{X}$ collagen may appear earlier than type II. Therefore, caution must be exercised in using type $\mathrm{X}$ collagen as a marker of chondrogenesis or chondrocyte hypertrophy (45). Type II collagen is synthesized as a homotrimeric procollagen molecule $[\alpha 1(\mathrm{II})]_{3}$ in cartilage and is the most abundant fibril-forming collagen within joints. Type XI collagen, a heterotrimeric collagen molecule $[\alpha 1(\mathrm{XI}) \alpha 2(\mathrm{XI})$ $\alpha 3(\mathrm{XI})$ ], forms the core of the type II collagen fibril for type II collagen fibrillogenesis and is responsible for fibril diameters in cartilage. Collagen type II and XI collagens co-polymerize with type IX collagen to form a heteropolymeric fibrillary framework that corresponds with the tensile strength of cartilage (46).

Although chondrogenesis is usually assessed with markers of the chondrocyte phenotype (including type II, X and XI collagen), the usefulness of these markers may need to be reconsidered given that expression of collagen (all types) may vary as a function of the duration of the culture period and the number of passages. In the present study, the cells cultured in the conditioned medium primarily expressed type I and type $X$ collagen, which may indicate dedifferentiation or hypertrophic processes. The human primary fibroblasts also expressed these markers at high levels. In contrast, cells differentiated in the HC-402-05a-condition medium did not present other hypertrophic markers; furthermore, they had significantly higher levels of desired chondrogenic markers (14). Cells cultured in the presence of TGF- $\beta 3$ also expressed high levels of type XI collagen in addition to type I and X collagens (Fig. 4), which is a desirable marker because it suggests that these cells present characteristics of mature and hypertrophic chondrocytes. Although the most accurate marker is type II collagen, this marker was not expressed in any of the cells. This may be because all cultured cells were obtained following the third passage or, alternatively, due to lack of sex determining region $Y$-box 5 and SOX6 expression, which are required for the production of type II collagen.
Indian hedgehog belongs to the hedgehog family and is involved in the regulation of chondrocyte proliferation and differentiation through a negative feedback loop with parathyroid hormone related protein (PTHrP), a hypertrophy regulator that acts in an IHH-dependent manner during chondrocyte proliferation and hypertrophy $(47,48)$. IHH activates expression of PTHrP and the resultant PTHrP protein signals through its receptor PTHR1 and inhibits excessive expression of $I H H$ to prevent hypertrophy and maintain the proliferating state in chondrocytes. Mak et al (49) demonstrated that IHH promotes chondrocyte hypertrophy independently of PTHrP through BMP and WNT/ $\beta$-catenin signaling. The canonical WNT/ $\beta$-catenin pathway controls the function of $\mathrm{IHH}$, via WNT family member 9a (WNT9a), which is involved in skeletogenesis. WNT9a signaling may inhibit the expression of WNT family member 4 , which is characteristic for prehypertrophic chondrocytes (50). In mature proliferating chondrocytes, the production of IHH is increased, which has a visible effect on the neighbouring cells and results in activation of their PTCH1 receptor. This results in elevated production of PTHrP and slower cell differentiation. Insulin-like growth factor 1 is a major growth-promoting signal for skeletogenesis: It suppresses PTHrP, thus inducing VEGF expression and controlling the production of hypoxia-inducible factor 1-induced angiogenesis (51). The IHH signaling pathway also interacts with RUNX2 and RUNX3 during chondrocyte proliferation and differentiation. Induction of osteoblast differentiation by $\mathrm{IHH}$ requires other effectors, that remain to be identified, besides RUNX2. Inhibition of IHH activity regulating RUNX2 and RUNX3 in the perichondrium during chondrogenesis triggers limb shortening $(52,53)$.

IHH expression was observed in all the cultured cells, with the highest levels of expression in cells differentiated in the conditioned medium. These cells may be from the pre-hypertrophic stage that is enriched in proliferative cells (Fig. 5). These cells did not present the parathyroid hormone at the mRNA level, a finding that indicated the presence of a negative feedback loop between IHH and PTHrP. The selectivity of this marker is only moderate because it was expressed by negative controls, in particular PHDFs, but there was a difference between the cells differentiated in the TGF- $\beta 3$ medium and the conditioned medium. In addition, the chondrocytes obtained from TGF- $\beta 3$-mediated chondrogenesis in vitro demontrated decreased levels of $I H H$ with elevated expression of PTHrP (Fig. 5). This result also confirmed the existence of a negative feedback loop between IHH and PTHrP and consequently the hypertrophic features of these cells. The value of PTHrP as a specific marker of hypertrophy is significantly diminished by the fact that $P T H r P$ is also highly expressed in PHDFs.

PTCH1 is a transmembrane receptor expressed in the cartilage-bone interface, the perichondrium, and in proliferating chondrocytes. It negatively regulates and is transcriptionally activated by the Hedgehog signaling pathway, thus creating a negative autoregulatory feedback loop $(54,55)$. Sonic hedgehog is the most prominent member of Hedgehog family. It induces the activation of GLI family transcription factors regulating the transcription of target genes, including GLII and PTCHI during the generation of induced pluripotent cells from fibroblasts (56). 
Cells differentiated in the presence of TGF- $\beta 3$ possessed features characteristic for hypertrophic chondrocytes at the genetic level. They expressed $\mathrm{PTCH} 1$, which is negatively regulated by IHH, a hypertrophic marker. The negative feedback loop between PTCH1 and IHH was also demonstrated. Compared with cells cultured in the conditioned medium, $I H H$ expression was downregulated in cells differentiated with TGF- $\beta 3$, potentially due to activated PTCH1. However, it should be noted that high levels of PTCHI expression were observed in hiPSCs (Fig. 5). It is possible to ascribe this phenomenon to a reprogramming process rather than to the spontaneous chondrogenic differentiation of hiPSCs. For this reason, the selectivity of this marker for chondrogenesis in vitro is less valuable than would otherwise be expected.

The RUNX family of DNA-binding transcription factors control cell fate determination in a variety of tissues. They are essential for hematopoiesis, skeletal development, and development of the digestive and nervous systems. RUNX belongs to the small transcription factor family and is expressed in pre-hypertrophic and hypertrophic chondrocytes, indicating its involvement in cartilage development. Furthermore, there is evidence that RUNX2, a key regulator of osteoblast differentiation, is also involved in regulating chondrocyte and osteoclast differentiation, vascular invasion and periosteal bone formation. During cartilaginous condensation, RUNX2 forms a complex with RUNX3 to control early chondrocyte differentiation $(57,58)$. The expression and activity of $R U N X 2$ is regulated by a multiple growth factors, including fibroblast-like growth factor 2, TGF- $\beta$ /BMP-2 and parathyroid hormone (59). $R U N X 2$ is highly expressed in immature osteoblasts but its expression is abruptly downregulated during osteoblast maturation, when mature bone is formed. Hence, RUNX2 determines the stage of osteoblast maturation, bone maturity and the bone turnover rate, and is generally considered a major driver for the later stages of endochondral ossification $(60,61)$.

RUNX2 expression was particularly detectable in the chondrocyte-like cells differentiated in the presence of TGF- $\beta 3$ (Fig. 5). This finding suggests that differentiation in the presence of these growth factors, in contrast to culture in the conditioned medium, favours the creation of hypertrophic chondrocytes. Other results obtained in the present study also confirm this, particularly the strong association between $R U N X, F G F-2, T G F-\beta / B M P-2$, and PTHrP.

Finally, in terms of markers characteristic for chondrocytes with osteoarthritic properties and cells undergoing ossification, hiPSCs differentiated in TGF- $\beta 3$ medium expressed mRNA indicative of cartilage degradation (Fig. 6).

In terms of study limitations, this was a two-part study that demonstrated that hiPSCs differentiated in vitro acquire a characteristic gene expression profile. Although this gene expression profile is informative, it does not provide unambiguous data to ascertain the precise chondrogenic stage of the differentiated cells. In addition, due to the close interrelation among the pathways activated during chondrogenesis, it is difficult to identify the specific contribution of each pathway to the chondrogenic process. More research is required to elucidate this poorly understood area of chondrogenic differentiation. Thus, it is important to emphasize that the classification of markers in the present study is subjective and is based on the authors' knowledge and understanding of the available literature.

To conclude, in the present study, chondrocytes obtained by differentiating hiPSCs via EB formation in different mediums resulted in divergent gene profiles. Cells differentiated in the presence of TGF- $\beta 3$ expressed genes associated with hypertrophy, whereas hiPSCs differentiated in a medium conditioned with HC-402-05a cells expressed genes indicative of early and advanced chondrogenesis, thus indicating the superiority of this medium. The most promising gene markers of hiPSC differentiation were as follows: RUNX2, TGF- $\beta 2, T G F-\beta 3$, type XI collagen, type X collagen, PTHLH, $M M P-13$ and $V E G F$. Useful but less valuable markers included TGF- $\beta$ receptors and the remaining members of the TGF- $\beta$ superfamily.

The present study contributes to the development of a novel, cost-effective protocol based on the use of endogenous growth factors and metabolites in HC-402-05a-conditioned medium. Notably, this approach does not require the use of expensive exogenous growth factors. These preliminary results suggest that the conditioned medium is likely to be more efficient than the standard TGF- $\beta 3$-based protocol, which may result in hypertrophy. However, the chondrocyte-like cells obtained in these processes consist of a mixed population that includes partially and fully differentiated cells as well as undifferentiated cells. As a result, evaluation of the chondrogenic process is challenging. Furthermore, the origin of hiPSCs has a substantial impact on their further differentiation toward chondrocyte-like cells deriving from the same germ layer as the parental reprogrammed fibroblasts. The present study contributes to an improved understanding of chondrogenic differentiation and may help further the development of regenerative medicine with hiPSCs.

\section{Acknowledgements}

The authors would like to thank Mr. Bradley Londres for his assistance in editing the manuscript. The present study was supported by the National Science Centre (grant no. 2012/07/E/NZ3/01819).

\section{References}

1. Xie A, Nie L, Shen G, Cui Z, Xu P, Ge H and Tan Q: The application of autologous platelet-rich plasma gel in cartilage regeneration. Mol Med Rep 10: 1642-1648, 2014.

2. Saito T, Yano F, Mori D, Kawata M, Hoshi K, Takato T, Masaki H, Otsu M, Eto K, Nakauchi H, et al: Hyaline cartilage formation and tumorigenesis of implanted tissues derived from human induced pluripotent stem cells. Biomed Res 36: 179-186, 2015.

3. Tang J, Cui W, Song F, Zhai C, Hu H, Zuo Q and Fan W: Effects of mesenchymal stem cell on interleukin-1 $\beta$-treated chondrocytes and cartilage in a rat osteoarthritic model. Mol Med Rep 12: 1753-1760, 2015.

4. Suchorska WM, Augustyniak E and Łukjanow M: Genetic stability of pluripotent stem cells during anti-cancer therapies. Exp Ther Med 11: 695-702, 2016.

5. Sommer AG, Rozelle SS, Sullivan S, Mills JA, Park SM, Smith BW, Iyer AM, French DL, Kotton DN, Gadue P, et al: Generation of human induced pluripotent stem cells from peripheral blood using the STEMCCA lentiviral vector. J Vis Exp 2012: 4327, 2012.

6. Barczak W, Suchorska W, Rubiś B and Kulcenty K: Universal real-time PCR-based assay for lentiviral titration. Mol Biotechnol 57: 195-200, 2015. 
7. Ye J, Hong $\mathrm{J}$ and Ye F: Reprogramming rat embryonic fibroblasts into induced pluripotent stem cells using transposon vectors and their chondrogenic differentiation in vitro. Mol Med Rep 11: 989-994, 2015.

8. Oldershaw RA, Baxter MA, Lowe ET, Bates N, Grady LM, Soncin F, Brison DR, Hardingham TE and Kimber SJ: Directed differentiation of human embryonic stem cells toward chondrocytes. Nat Biotechnol 28: 1187-1194, 2010.

9. Phillips MD, Kuznetsov SA, Cherman N, Park K, Chen KG, McClendon BN, Hamilton RS, McKay RD, Chenoweth JG, Mallon BS and Robey PG: Directed differentiation of human induced pluripotent stem cells toward bone and cartilage: In vitro versus in vivo assays. Stem Cell Transl Med 3: 867-878, 2014.

10. Toh WS and Cao T: Derivation of chondrogenic cells from human embryonic stem cells for cartilage tissue engineering. Methods Mol Biol: Jul 12, 2014 (Epub ahead of print).

11. Mardani M, Hashemibeni B, Ansar MM, Zarkesh Esfahani SH, Kazemi M, Goharian V, Esmaeili $\mathrm{N}$ and Esfandiary $\mathrm{E}$ : Comparison between chondrogenic markers of differentiated chondrocytes from adipose deived stem cells and articular chondrocytes in vitro. Iran J Basic Med Sci 16: 763-773, 2013.

12. Lee HJ, Choi BH, Min BH and Park SR: Changes in Surface markers of human mesenchymal stem cells during the chondrogenic differentiation and dedifferentiation processes in vitro. Arthritis Rheum 60: 2325-2332, 2009.

13. Trzeciak T, Augustyniak E, Richter M, Kaczmarczyk J and Suchorska W: Induced pluripotent and mesenchymal stem cells as a promising tool for articular cartilage regeneration. J Cell Sci Ther 5: 4, 2014.

14. Suchorska WM, Augustyniak E, Richter M and Trzeciak T: Gene expression profile in human induced pluripotent stem cells: Chondrogenic differentiation in vitro-part A. Mol Med Rep 15: 2387-2401, 2017

15. Wróblewska J: A new method to generate human induced pluripotent stem cells (iPS) and the role of the protein KAP1 in epigenetic regulation of self-renewal. $\mathrm{PhD}$ dissertation. Poznan University of Medical Sciences. http://www.wbc.poznan. pl/Content/373798/index.pdf, 2015.

16. Suchorska WM, Lach MS, Richter M, Kaczmarczyk J and Trzeciak T: Bioimaging: An useful tool to monitor differentiation of human embryonic stem cells into chondrocytes. Ann Biomed Eng 44: 1845-1859, 2016.

17. Nejadnik H, Diecke S, Lenkov OD, Chapelin F, Doing J, Tong X, Derugin N, Chan RC, Gaur A, Yang F, et al: Improved approach for chondrogenic differentiation of human induced pluripotent stem cells. Stem Cell Rev 11: 242-253, 2015.

18. Livak KJ and Schmittgen TD: Analysis of relative gene expression data using real-time quantitative PCR and the 2(-Delta Delta C (T)) Method. Methods 25: 402-408, 2001.

19. Polacek M, Bruun JA, Johansen O and Martinez I: Comparative analyses of the secretome from dedifferentiated and redifferentiated adult articular chondrocytes. Cartilage 2: 186-196, 2011.

20. Meng W, Xia Q, Wu L, Chen S, He X, Zhang L, Gao Q and Zhou H: Downregulation of TGF-beta receptors types II and III in squamous cell carcinoma and oral carcinoma-associated fibroblasts. BMC Cancer 11: 88, 2011.

21. Derynck R and Zhang YE: Smad-dependent and Smad-independent pathways in TGF-beta family signaling. Nature 425: 577-584, 2003.

22. Keller B, Yang T, Chen Y, Munivez E, Bertin T, Zabel B and Lee B: Interaction of TGF $\beta$ and BMP signaling pathways during chondrogenesis. PLoS One 6: e16421, 2011.

23. Shen B, Wei A, Tao H, Diwan AD and Ma DD: BMP-2 enhances TGF-beta3-mediated chondrogenic differentiation of human bone marrow multipotent mesenchymal stromal cells in alginate bead culture. Tissue Eng Part A 15: 1311-1320, 2009.

24. Chen G, Deng C and Li YP: TGF- $\beta$ and BMP signaling in osteoblast differentiation and bone formation. Int J Biol Sci 8: 272-288, 2012

25 . Huang $\mathrm{F}$ and Chen YG: Regulation of TGF- $\beta$ receptor activity. Cell Biosci 2: 9, 2012.

26. Shen J, Li S and Chen D: TGF- $\beta$ signaling and the development of osteoarthritis. Bone Res 2: 14002, 2014.

27. Watabe T and Miyazono K: Roles of TGF-beta family signaling in stem cell renewal and differentiation. Cell Res 19: 103-115, 2009.

28. Wang W, Rigueur D and Lyons KM: TGF $\beta$ signaling in cartilage development and maintenance. Birth Defects Res C Embryo Today 102: 37-51, 2014.
29. Tan F, Quian C, Tanq K, Abd-Allach SM and Jing N: Inhibition of transforming growth factor $\beta$ (TGF- $\beta$ ) signaling can substitute for Oct4 protein in reprogramming and maintain pluripotency. J Biol Chem 290: 4500-4511, 2015.

30. Blaney Davidson EN, Vitters EL, van den Berg WB and van der Kraan PM: TGF beta-induced cartilage repair is maintained but fibrosis is blocked in the presence of Smad7. Arthritis Res Ther 8: R65, 2006.

31. Tekari A, Luginbuehl R, Hofstetter W and Egli RJ: Transforming growth factor beta signaling is essential for the autonomous formation of cartilage-like tissue by expanded chondrocytes. PLoS One 10: e0120857, 2015.

32. Li F and Niyibizi C: Cells derived from murine induced pluripotent stem cells (iPSC) by treatment with members of TGF-beta family give rise to osteoblasts differentiation and form bone in vivo. BMC Cell Biol 13: 35, 2012.

33. Sun J, Li J, Li C and Yu Y: Role of bone morphogenetic protein-2 in osteogenic differentiation of mesenchymal stem cells. Mol Med Rep 12: 4230-4237, 2015.

34. Shu B, Zhang M, Xie R, Wang M, Jin H, Hou W, Tang D, Harris SE, Mishina Y, O'Keefe RJ, et al: BMP-2, but not BMP-4, is crucial for chondrocyte proliferation and maturation during endochondral bone development. J Cell Sci 124: 3428-3440, 2011.

35. Matsubara T, Kida K, Yamaguchi A, Hata K, Ichida F, Meguro H, Aburatani $\mathrm{H}$, Nishimura $\mathrm{R}$ and Yoneda T: Bmp2 regulates Osterix through Msx2 and Runx2 during osteoblast differentiation. J Biol Chem 283: 29119-29125, 2008

36. Sun Z, Zhang Y, Yang S, Jia J, Ye S, Chen D and Mo F: Growth differentiation factor 5 modulation of chondrogenesis of self-assembled constructs involves gap junction-mediated intercellular communication. Dev Growth Differ 54: 809-817, 2012.

37. Coleman CM, Vaughan EE, Browe DC, Mooney E, Howard L and Barry F: Growth differentiation factor-5 enhances in vitro mesenchymal stromal cell chondrogenesis and hypertrophy. Stem Cells Dev 22: 1968-1976, 2013.

38. Hatakeyama Y, Hatakeyama J, Maruya Y, Oka K, Tsuruga E, Inai $\mathrm{T}$ and Sawa Y: Growth differentiation factor 5 (GDF-5) induces matrix metalloproteinase 2 (MMP-2) expression in peridontal ligament cells and modulates MMP-2 and MMP-13 activity in osteoblasts. Bone and Tissue Regeneration Insights 3 : $1-10,2010$.

39. Furumatsu T, Tsuda M, Taniguchi N, Tajima $\mathrm{Y}$ and Asahara $\mathrm{H}$ : Smad3 induces chondrogenesis through the activation of SOX9 via CREB-binding protein/p300 recruitment. J Biol Chem 280: 8343-8350, 2005

40. Zhang M, Wang M, Tan X, Li TF, Zhang YE and Chen D: Smad3 prevents beta-catenin degradation and facilitates beta-catenin nuclear translocation in chondrocytes. J Biol Chem 285: 8703-8710, 2010.

41. Chen CG, Thuillier D, Chin EN and Alliston T: Chondrocyte-intrinsic Smad3 represses Runx2-inducible matrix metalloproteinase 13 expression to maintain articular cartilage and prevent osteoarthritis. Arthritis Rheum 64: 3278-3289, 2012.

42. Savontaus $M$, Ihanamäki $T$, Perälä $M$, Metsäranta $M$, Sandberg-Lall $M$ and Vuorio E: Expression of type II and IX collagen isoforms during normal and pathological cartilage and eye development. Histochem Cell Biol 110: 149-159, 1998.

43. Krug D, Klinger M, Haller R, Hargus G, Büning J, Rohwedel J and Kramer J: Minor cartilage collagens type IX and XI are expressed during embryonic stem-cell derived in vitro chondrogenesis. Ann Ant 195: 88-97, 2013.

44. Goessler UR, Bugert P, Bieback K, Baisch A, Sadick H, Verse T, Klüter H, Hörmann K and Riedel F: Expression of collagen fiber-associated proteins in human septal cartilage during in vitro dedifferentiation. Int J Mol Med 14: 1015-1022, 2004.

45. Mwale F, Stachura D, Roughley P and Antoniou J: Limitations of using aggrecan and type $\mathrm{X}$ collagen as markers of chondrogenesis in mesenchymal stem cell differentiation. J Orthop Res 24: 1791-1798, 2006

46. McAlinden A, Traeger G, Hansen U, Weis MA, Ravindran S, Wirthlin L, Eyre DR and Fernandes RJ: Molecular properties and fibril ultrastructure of type II and XI collagens in cartilage of mice expressing exclusively the $\alpha 1$ (IIA) collagen isoform. Matrix Biol 34: 105-113, 2014.

47. Ma RS, Zhou ZL, Luo JW, Zhang H and Hou JF: The Ihh signal is essential for regulating proliferation and hypertrophy of cultured chicken chondrocytes. Comp Biochem Physiol B Biochem Mol Biol 166: 117-122, 2013. 
48. Katoh Y and Katoh M: Hedgehog signaling pathway and gastrointestinal stem cell signaling network (Review). Int J Mol Med 18: 1019-1023, 2006.

49. Mak KK, Konenberg HM, Chuang PT, Mackem S and Yang Y: Indian hedgehog signals independently of PTHrP to promote chondrocyte hypertrophy. Development 135: 1947-1956, 2008.

50. Später D, Hill TP, O'sullivan RJ, Gruber M, Conner DA and Hartmann C: Wnt9asignaling is required for joint integrity and regulation of Ihh during chondrogenesis. Development 133 3039-3049, 2006.

51. Wang Y, Cheng Z, Elalieh HZ, Nakamura E, Nguyen MT, Mackem S, Clemens TL, Bikle DD and Chang W: IGF-1R signaling in chondrocytes modulates growth plate development by interacting with the PTHrP/Ihh pathway. J Bone Miner Res 26: 1437-1446, 2011.

52. Kim EJ, Cho SW, Shin JO, Lee MJ, Kim KS and Jung HS: Ihh and Runx2/Runx3 signaling interact to coordinate early chondrogenesis: A mouse model. PLoS One 8: e55296, 2013.

53. Tu X, Joeng KS and Long F: Indian hedgehog requires additional factors besides Runx2 to induces osteoblast differentiation. Dev Biol 362: 76-82, 2012.

54. Liu Z, Xu J, Colvin JS and Ornitz DM: Coordination of chondrogenesis and osteogenesis by fibroblast growth factor 18 . Genes Dev 16: 859-869, 2002
55. Bruce SJ, Butterfield NC, Metzis V, Town L, McGlinn E and Wicking C: Inactivation of Patched 1 in the mouse limb has novel inhibitory effects on the chondrogenic program. J Biol Chem 285: 27967-27981, 2010.

56. Moon JH, Heo JS, Kim JS, Jun EK, Lee JH, Kim A, Kim J, Whang KY, Kang YK, Yeo S, et al: Reprogramming fibroblasts into induced pluripotent stem cells with Bmi1. Cell Res 21: 1305-1315, 2011

57. Vimalraj S, Arumugam B, Miranda PJ and Selvamurugan N: Runx2: Structure, function, and phosphorylation in osteoblast differentiation. Int J Biol Macromol 78: 202-208, 2015.

58. Sun J, Zhou H, Deng Y, Zhang Y, Gu P, Ge S and Fan X: Conditioned medium from bone marrow mesenchymal stem cells transiently retards osteoblast differentiation by downregulating runx2. Cells Tissues Organs 196: 510-522, 2012.

59. Ann EJ, Kim HY, Choi YH, Kim MY, Mo JS, Jung J, Yoon JH, Kim SM, Moon JS, Seo MS, et al: Inhibition of Notch1 signaling by Runx2 during osteoblast differentiation. J Bone Miner Res 26 : 317-330, 2011.

60. Komori T: Regulation of bone development and extracellular matrix protein genes by RUNX2. Cell Tissue Res 339: 189-195, 2010.

61. Du F, Wu H, Zhou Z and Liu YU: microRNA-375 inhibits osteogenic differentiation by targeting runt-related transcription factor 2. Exp Ther Med 10: 207-212, 2015. 